\title{
HABITAÇÃO SOCIAL NO CENTRO DE PRESIDENTE PRUDENTE-SP
}

Camila Aline da Silva Le Bourlegat, Mayara Pissutti Albano Vieira, Fabrícia Dias da Cunha de Moraes Fernandes Borges

Universidade do Oeste Paulista - UNOESTE, curso de Arquitetura e Urbanismo, Presidente Prudente, SP. E-mail: fabricia.arquiteta@gmail.com

\section{RESUMO}

O processo de urbanização no Brasil e as direções tomadas pelas políticas públicas provocaram o crescimento horizontal das cidades e a alocação da população de baixa renda nas franjas da malha urbana onde por vezes a infraestrutura é precária e as longas distâncias aumentam os custos com transporte e colabora com a acentuação do processo de segregação socioespacial. Inserir habitação nos centros urbanos em edifícios subutilizados ou não utilizados pode ser uma alternativa para a situação apresentada. A presente pesquisa visa analisar a viabilidade de um edifício no centro da cidade de Presidente Prudente - SP que apresente potencialidade para abrigar um conjunto de habitação social e propor diretrizes para o projeto arquitetônico, para tal serão realizadas pesquisas bibliográficas, documentais e de campo.

Palavras chave: Habitação Social, Centro urbano, Urbanização, Segregação Sócioespacial, Presidente Prudente - SP

\section{SOCIAL HOUSING IN THE CENTER OF PRESIDENT PRUDENTE-SP}

\section{ABSTRACT}

The urbanization process in Brazil and the directions taken by the public policies provoked the horizontal growth of the cities and the allocation of the population of low income in the fringes of the urban network where sometimes the infrastructure is precarious and the long distances increase the costs with transport and collaborates With the accentuation of the socio-spatial segregation process. Placing housing in urban centers in underused or unused buildings may be an alternative to the situation presented. This research aims at analyzing the feasibility of a building in the center of the city of Presidente Prudente - SP that presents the potential to shelter a set of social housing and propose guidelines for the architectural project, for this will be done bibliographic, documentary and field research.

Keywords: Social Housing, Urban Center, Urbanization, Socio-spatial Segregation, Presidente Prudente - SP

\section{INTRODUÇÃO}

O processo de urbanização do Brasil, na segunda metade do século XX apresentou intensificação, e a partir da década de 1970 a população urbana ultrapassa a população residente na área rural, acentuando a crise urbana (SANTOS, 2005). Tal fato impulsionou um enorme movimento de construção de cidade legal e ilegal, com forte expansão da malha voltada a áreas habitacionais, contudo, juntamente com a necessidade de moradia, há necessidades como saneamento básico, transportes, e demais sistemas de infraestrutura e equipamentos urbanos que deem suporte às necessidades da população de baixa renda (MARICATO, 2001).

A partir de 1964, com a instituição do Banco Nacional da Habitação (BNH), pelo Regime Militar, a produção das cidades brasileiras teve suas características alteradas pela política habitacional estabelecida através de duas vertentes: uma direcionada para a classe média, que 
promoveu a verticalização ocasionada pelos edifícios de apartamentos e, uma segunda vertente, que provocou a acentuação do processo de periferização herdado do adensamento e crescimento das cidades que deslocou a moradia das classes mais baixas para as franjas da malha urbana (BONATES, 2008).

Segundo Maricato (2001, p. 20), "Infelizmente o financiamento imobiliário não impulsionou a democratização do acesso à terra", e como reflexo da exclusão social e segregação espacial nítida no modelo de urbanização adotado no país, o mercado não se abriu para a maioria das pessoas que necessitavam de moradia - as pertencentes às classes populares.

Uma alternativa interessante para a habitação de interesse social é a inserção da mesma nos centros urbanos, nas sobrelojas ou em edifícios subutilizados ou não utilizados. Os centros possuem infraestrutura excepcional comparado às demais áreas da cidade e, ao longo do tempo vêm sofrendo um esvaziamento significativo simultaneamente com o crescimento extensivo das periferias que carecem muitas vezes desta infraestrutura.

A extensão horizontal das cidades acarreta em obras caras de infraestrutura, colabora para a complexidade de circulação, que resulta na imposição de pesados custos aos moradores das periferias com transportes. Por outro lado, os bairros centrais acabam por se tornarem ociosos em horários não comerciais, ocasionando um abandono no período noturno e nos fins de semana.

O presente artigo apresenta a escolha de um edifício no centro urbano de Presidente Prudente - SP, que esteja subutilizado ou não utilizado e propor diretrizes para sua reutilização através da inserção de um conjunto de habitação social.

\section{METODOLOGIA}

A metodologia utilizada nesta pesquisa foi desenvolvida através da investigação qualitativa, utilizando-se de levantamento bibliográfico, de pesquisa documental, de levantamentos físicos arquitetônicos in locu do centro da referida cidade e posteriormente do edifício que escolhido.

Num primeiro momento foi realizado levantamento bibliográfico em livros e periódicos com as principais obras referentes ao assunto estudado. Numa segunda fase, foram desenvolvidas pesquisas documentais para verificação do projeto do edifício escolhido através dos documentos existentes no arquivo histórico municipal e em websites que possuem materiais relativos à história das cidades da região pertencentes à acervos particulares. A análise documental é, conforme afirma Lüdke e André (1986, p.38), uma "uma técnica valiosa de abordagem de dados qualitativos, seja complementando informações obtidas por outras técnicas, seja desvelando aspectos novos de um tema ou problema".

Posteriormente foram realizados levantamentos in locu, para a realização de levantamentos fotográficos. Após a conclusão das fases iniciais desenvolveu-se as diretrizes projetuais para inserção do conjunto de habitação de interesse social seguindo as políticas habitacionais vigentes.

\section{HABITAÇÃO NO CENTRO URBANO}

Os centros urbanos são considerados os bairros mais dinâmicos da vida urbana, visto que recebem diariamente grande fluxo de pessoas, veículos e prestação de serviços. Na história, geralmente, estes são escolhidos como locais para as instalações públicas e religiosas, fortalecendo assim a centralidade pela soma de todas estas atividades (VARGAS; CASTILHO, 2009).

Segundo Guzmán (2003, apud MENEZES, 2015, p. 19), “Nas últimas décadas, as áreas centrais de boa parte das cidades latino-americanas passaram de "centros da vida e da diversidade" para "centros de conflitos, de exclusão e de pobreza". O processo de deterioração ou degradação de tais áreas, a partir de 1950 foi intensificado no Brasil, causado principalmente pelo crescimento e expansão do espaço urbano (VARGAS; CASTILHO, 2009). No Brasil e nos países de industrialização consideradas tardias, começam a ter uma preocupação com a recuperação dos 
centros apenas em 1990, associado à valorização turística das cidades, enquanto que em várias cidades Europeias e Norte Americanas inicia-se em 1970 com o foco retomada das áreas abandonadas pelas indústrias (LUCHIARI, 2005).

Muito tem se falado nos últimos tempos sobre a questão da revitalização dos centros históricos, com discussões opostas. De um lado ela é estratégia de preservação e revalorização de locais das cidades degradados; por outro como processo de gentrificação ${ }^{1}$, pois isto implica na expulsão dos moradores permanentes. Por causa desta adoção excepcional de infraestrutura em relação a outros locais da cidade, o centro vem sofrendo um esvaziamento, resultando em um crescente nas periferias criando novos problemas de infraestrutura (MARICATO, 2008).

Em resposta a esta crise urbana, a diversidade de uso no centro que Jacobs (2014) propõe, pode amenizar vários problemas urbanos encontrados hoje. Através do incentivo à implantação de mais de um uso principal, para assim, se ter fluxo de pessoas em horários diferentes. Também deve haver mistura de prédios antigos e novos, e ter alta concentração de pessoas morando no local. Entretanto a prática desta teoria não se encontra no centro de Presidente Prudente que em grande maioria dos edifícios possui uso exclusivamente comercial, ou seja, acaba reforçando vários problemas sociais, como por exemplo a segregação espacial urbana em conjunto com a falta de segurança e sensação de perigo.

O descaso com os centros históricos acontece em todo o país, e em Presidente Prudente SP não seria diferente. O centro da cidade, considerado centro histórico o qual tem relação com o início da cidade, em sua grande maioria atende a necessidade de serviços diversos apenas, com poucas residências no local, estes com moradores mais antigos, fazendo com que a população permanente do centro seja composta de pessoas mais idosos. Desta forma, os novos bairros nas franjas da malha urbana consolidada acabam atendendo a necessidade de moradia da população de baixa renda, dificultando a vida de seus habitantes em relação ao acesso à transporte, já que esta população geralmente trabalha longe de suas casas.

Em Presidente Prudente, de acordo com Honda (2013), nos primeiros anos de origem da cidade a vila Goulart assumiu o papel de centro comercial com residências de famílias mais ricas; já a vila Marcondes as residências eram de família com menor poder aquisitivo, e passou a atrair as empresas agrícolas.

No ano de 1968 foi construído então a primeira habitação social na cidade, o Parque Continental, localizado na franja urbana e financiado pelo Banco Nacional de Habitação (BNH), (HONDA, 2013). A partir de então, a localização periférica dos conjuntos de habitação social se reproduz na maior parte dos casos implantados na referida cidade, reforçando desta feita a necessidade de discutir o assunto abordado no presente trabalho.

\section{ESTUDO DE CASO, O HOTEL MUNICIPAL DE PRESIDENTE PRUDENTE}

Ao caminhar pelo centro histórico de Presidente Prudente, não se encontrará obras monumentais da arquitetura do passado, pois respondem as condições econômicas modestas, mas ricas em registros da sociedade que sucedem o processo urbano (HIRAO; FLOETER, 2012), entretanto para Ricoeur (2003, p. 10), a memória consiste em "fazer presente, não o que já existe, senão, o que tem existido por meio do que já não existe mais" (apud MARTINS, 2016, p.25).

Desta forma, o local escolhido para a implantação da habitação de interesse social é o edifício do Antigo Hotel Municipal, um importante edifício histórico, com características arquitetônicas ecléticas e influência germânica está localizado na esquina entre as ruas Dr. Gurgel

\footnotetext{
${ }^{1}$ Gentrificação no dicionário Priberam (2012), significa “Processo de valorização imobiliária de uma zona urbana, geralmente acompanhada da deslocação dos residentes com menor poder econômico para outro local e da entrada de residentes com maior poder econômico"

Colloquium Socialis, Presidente Prudente, v. 01, n. Especial 2, Jul/Dez, 2017, p.722-727. DOI: 10.5747/cs.2017.v01.nesp2.s0219
} 
e Joaquim Nabuco. A escolha do local para intervenção se deu através de várias análises que abordaram a fundamentação teórica deste trabalho.

Segundo Resende (2006) em 1929 o hotel foi construído pelo Dr. Romeu Leão, com a função de abrigar o segundo hospital da cidade de Presidente Prudente, com o nome de Sanatório São Paulo, com quinze leitos, entretanto em 1934 por motivos de falência, o Sanatório foi vendido à uma família alemã, ao Dr. Domingos Leonardo Cerávolo, passando então a ser chamado Hotel Municipal.

De fato, este edifício guarda boas histórias em seus corredores e na memória de quem viveu nesta época, de acordo com Resende (2006), os detalhes da construção lembravam edifícios portugueses, principalmente pelos azulejos lusitanos abaixo das janelas; e sobre elas, pequenas abas, com cobertura de telhas.

Com o passar do tempo, tem ocorrido várias alterações desde sua criação em 1929 até os dias atuais, o descaso com a memória local existente é nítido ao analisarmos as mudanças cronológicas (figura 1), principalmente na fachada principal do edifício.

Figura 1 - Cronologia da mudança ocorrida no Hotel Municipal

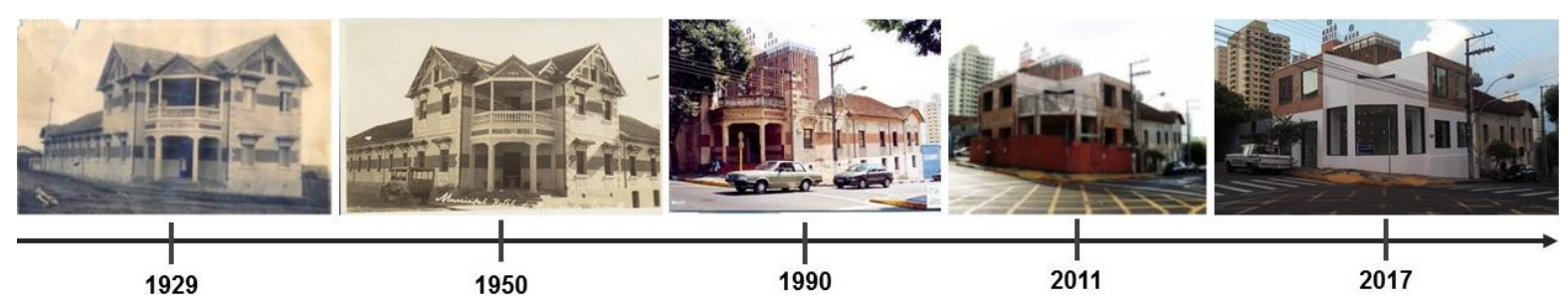

Fonte: Acervo do Museu Municipal. Modificado pelo autor (2017).

Por sua localização privilegiada e pelo abandono em que se encontra a maior parte do edifício, este foi escolhido para análise e diretrizes para um possível futuro projeto de um conjunto habitacional no centro urbano.

Para esta intervenção é preciso que a habitação tenha qualidade, para o morador viver com satisfação, tranquilidade e conforto. Qualidade que corresponde a tipologia da construção, a relação com o usuário que caracterize a população alvo para o projeto, atribuindo assim um programa de necessidades adequado, conforto térmico e acústico, e viabilidade econômica, social, ambiental e urbana (MARTINS, 2016).

Segundo Maricato (2008), de acordo com as políticas urbanas, a habitação social em centros históricos não precisa esperar por modelos pilotos nacionais, mas sim o governo municipal poderá tentar incluir a política de moradia social em áreas centrais, independente de iniciativas em outros níveis de governos.

\section{DIRETRIZES PROJETUAIS}

O antigo hotel municipal, tem uma área aproximadamente de $1915.32 \mathrm{~m}^{2}$, este encontra-se em ruínas, deste modo deverá ser resguardado a história e memória existente no prédio, em suas dependências e na área vazia ao lado poderá ser usado também para implantação da habitação de interesse social, entretanto deverá respeitar o gabarito de altura no skyline do entorno. Atenderá o público ao qual o Programa Minha Casa Minha Vida se destina e se enquadrem na faixa 2, ou seja, o trabalhador que recebe até três salários.

Após vários estudos sobre intervenção em edifícios antigos e também sobre o conceito de restauro, foi escolhida a teoria segundo Cesari Brandi que descreve e orienta a não cometer o falso histórico, buscando o respeito ao patrimônio e seu caráter original sem esconder as intervenções ocorridas (BRANDI, 2008). 
Desta forma parte do antigo hotel que foi totalmente demolido não será reconstruído, entretanto no lugar será implantado novas moradias com características estéticas contemporânea; assim também no bloco da esquina o qual foi parcialmente descaracterizado na década de 1990, será retirado o revestimento e mantido o original do edifício, pois entende-se que este não agrega nenhum valor ao edifício nem a população local. $O$ pátio central do antigo hotel que hoje abriga o estacionamento privado para comerciantes será mantido, este deverá ser o ponto de encontro e de interação dos habitantes; já na parte dos fundos onde está inserida a área verde, será instalado respeitando a topografia do terreno um novo bloco contemporâneo para habitação com até quatro pavimentos, de forma com que não afete o gabarito de altura do antigo hotel municipal. Para que assim mantenha-se a identidade existente do hotel, mas com uma nova função, a de residência.

\section{CONSIDERAÇÕES FINAIS}

Após realizar todas as análises e discussões teóricas, foi identificada a importância de preservar a memória existente no antigo edifício, e a necessidade de trazer a moradia para o centro de Presidente Prudente, fato este colaborará para que seja uma área mais viva e igualitária.

A habitação de interesse social no centro da cidade pode dar oportunidade de uso igual para todos os segmentos da população, a integração social de camadas de baixa renda na cidade sem discriminação, segregação ou exclusão social, trazendo um benefício inestimável à comunidade e evitando que edifícios e infraestrutura instalados sejam abandonados ou mal aproveitados.

\section{REFERÊNCIAS BIBLIOGRÁFICAS}

BONATES, Maria Fialho. O Programa de Arrendamento Residencial - PAR: acesso diferenciado à moradia e à cidade. Revista de Pesquisa em Arquitetura e Urbanismo, v.7, n. 1, p. 147-164, 2008. Disponível em: http://www.arquitetura.eesc.usp.br/revista risco/Risco7-pdf/02 art10 risco7.pdf. Acesso em: 8 fev 2016.

BRANDI, Cesare. Teoria da Restauração. 3 ed. Cotia. Ateliê Editorial, 2008.

HIRAO, Hélio; FLOETER, Roberto. O Patrimônio Arquitetônico e Urbanístico de Presidente Prudente: O Possível Preservado. TOPOS, V. 6, N² 2, p. $53-68.2012$

HONDA, Sibila Leão. Política Habitacional e o Capital Privado em Presidente Prudente-SP. R. Pol. Públ., São Luís, v. 17, n.2, p. 446 - 454, jul./dez. 2013

JACOBS, Jane. Morte e Vida de Grandes Cidades. 3atiragem. São Paulo: WMF Martins Fontes, 2014.

LUCHIARI, Maria Tereza. Centros Históricos: Mercantilização e Territorialidades do Patrimônio Cultural Urbano. Anais do X Encontro de Geógrafos da América Latina. Universidade de São Paulo, 2005.

LÜDKE, Menga; ANDRÉ, Marli. E. D. A. Pesquisa em educação: abordagens qualitativas. São Paulo: EPU, 1986.

MARICATO, Ermínia. Brasil cidades: alternativas para a crise urbana. Petrópolis, RJ: Vozes, 2001.

MARTINS, Juliana Cavaline. Habitação Social em Centros Urbanos Consolidados: Análise Dialógica desde o Percurso do Projeto ao uso Social: São Paulo (Brasil) e Roma (Itália). Dissertação 
apresentada ao Programa de Pós-graduação em Arquitetura e Urbanismo da Faculdade de Arquitetura, Artes e Comunicação da Universidade Estadual Paulista "Júlio de Mesquita Filho", campus de Bauru, 2016

MENEZES, Larissa Rodrigues. Habitar no Centro Histórico: A Habitação de Interesse Social como Instrumento de Reabilitação do Centro Histórico de Recife. Dissertação apresentada ao Programa de Pós-graduação em Desenvolvimento Urbano da Universidade Federal de Pernambuco. 2015

RESENDE, B. Raízes Prudentinas 2. São Paulo: Editorial Alexandre Alencar. 2006.

RESENDE, B. Raízes Prudentinas 3. Presidente Prudente - SP, 2012.

SANTOS, Milton. A urbanização brasileira. 5.ed. São Paulo: Universidade de São Paulo, 2005.

VARGAS, Helena; CASTILHO, Ana Luisa. Intervenções em Centros Urbanos: Objetivos, estratégicas e resultados. 2 ed. Ver. E atual. Barueri, SP: Manole, 2009. 